\title{
Facts vs. Stories - Assessment and Conventional Signals as Predictors of Freelancers' Performance in Online Labor Markets
}

\author{
Christian Holthaus \\ TU Darmstadt \\ christian.holthaus@stock-homburg.de
}

\author{
Ruth M. Stock \\ TU Darmstadt \\ rsh@stock-homburg.de
}

\begin{abstract}
This paper investigates how freelancers' use of signals predicts earnings in online labor markets. Extant literature has questioned the usefulness of some assessment signals to evaluate a freelancer's quality. We find that conventional signals - signals based on non-verifiable information - can be predictors of higher revenue, when they are based on anecdotes of positive past events (self-promotion). However, mere kindness and flattery towards the customer (ingratiation) is negatively associated with a freelancers' earnings in OLM. Moreover, we find evidence that the number of tests performed on the platform is significantly associated with higher earnings - with each test that is added to the profile a freelancer's revenue increases by $4.1 \%$. We base our analysis on a sample of 1065 freelancers using objective financial earnings data, independent codings and survey data.
\end{abstract}

\section{Introduction}

There has been a growing number of research on "online labor markets" (OLM), online platforms for individuals and organizations "to quickly identify short-term workers who have skills required for particular, often one-time, tasks" [1]. However, as contracts are negotiated very quickly, independent of time and space and with minimized personal contact, increased information asymmetry yields insecurity regarding the hiring process. Thus, clients have to rely on diverse factors and cues to judge if a particular freelancer is likely to perform well.

A prominent factor are signals visible on a freelancer's profile page. Signaling is a process in which "one party (termed the agent) credibly conveys some information about itself [through different signals] to another party (the principal)" [2]. This information in the form of signals is costly. Costs associated with sending the signal outweigh the benefits of sending if the sender does not possess the respective qualities [3]. In turn, costly signals may reduce information asymmetry and are assumed to be beneficial for forming contractual relationships thus resulting in higher earnings and revenue for the freelancer.

Accordingly, signaling literature has focused on the performance impact of signals in different markets and contexts, such as markets of public goods [4], the job market [3], the stock market [5] and the consumer market [6]. There are some studies in extant literature that have applied signaling theory to online labor markets. Signals assessed by this literature stream include the number of portfolio items [7], and the presence of a top rated status [8 9]. However, for some signals, such as ratings, literature mentions an upward bias and the ability to reduce information asymmetry is questionable [10 $11]$.

To date, extant literature in online labor markets has focused on "assessment signals" - verifiable and costly information, that can be directly validated by the receiver, such as ratings, tests and portfolio-items [12]. However, in highly competitive environments like online labor markets, freelancers do not solely rely on these types of signals to attract customers and stand out from the crowd.

In fact, freelancers make extensive use of so called "conventional signals" [12] that express intentions, anecdotes and opinions of the sender, such as self-promotion - an individual's claims to possess certain qualities. In contrast to assessment signals, these signals are not costly and cannot be directly validated. Surprisingly, literature on online labor markets has largely neglected conventional signals and their implications. Additionally, recent studies on assessment signaling neglect the fact that there might be other factors involved in signaling such as character traits and skills. To fill this gap, this study addresses the following research question: 
How do assessment signals and conventional signals affect freelancers' performance? We assess the financial dimension of buyer supply exchanges a freelancer's total earnings in USD for a period of one year - to reflect freelancers' performance [1314]. Measuring the earnings as a proxy of freelancing success has major benefits compared to other success measures, e.g., a natural unit that is easily interpreted, less bias than single source or dyadic data and the approximation of many dimensions of success in a single measure (customer satisfaction as well as successful management and sales activities) [15]. Additionally, we go beyond the level of visible signals and assess individual character traits habitual patterns of behavior that are stable over time [16] and key skills / individual differences that might affect performance in OLM. Moreover, we add other variables that are likely to influence a freelancer's earnings, such as a freelancer's availability, past project experience, education level and english verbal proficiency.

Our study contributes to extant literature in three ways. First, this study is the first to contrast conventional signals with assessment signals in online labor markets and shows that their performance implications differ. Thus, the research broadens the spectrum of signaling theory and opens up new avenues for OLM research. It helps to better understand the complexity of signaling behavior in OLM and offers various new signaling types future research could use to better assess performance in OLM. At the same time, we enable clients to infer crucial job related factors and improve their hiring decisions.

Second, we build our analysis on earnings, an outcome measure that is largely neglected in OLM research. Accordingly, we extend literature by pointing to possible differences between hiring decisions and financial outcomes as a proxy for performance in OLM.

Third, stressing the differences between signaling types contributes to research and practice on the design of OLM platforms, e.g., the optimal position of signaling spots (e.g., test scores, self-descriptions) on profile pages according to their relevance.

We obtain self-report measures of character traits, objective measures of performance and various assessment signals as well as measures of conventional signals as perceived by third raters.
Figure 1: Conceptual Framework

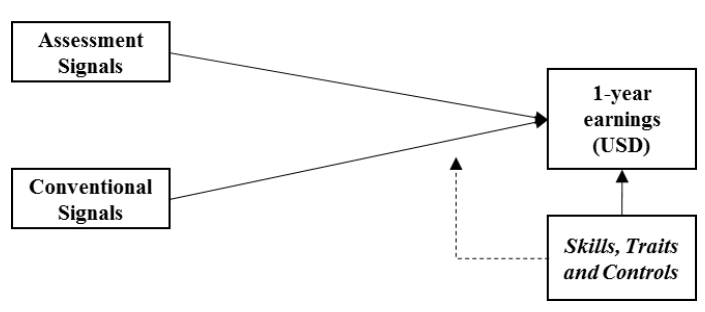

\section{Literature review}

\subsection{Online labor markets and related fields}

In information science, particularly in economics and accounting, there is an emerging body of literature on online labor markets, defined as online "tool for individuals and organizations to quickly identify short-term workers [- freelancers -] who have skills required for particular, often one-time, tasks." [1].

Thus, freelancing in the light of this study is the completion of major or minor business tasks by an individual in an online market place - the online labor market. The most important pillars of freelancing in online labor markets are the online representation of the freelancer by a profile page and the creation of an online reputation (e.g., via reviews and past jobs). Valuable candidates are virtually assessed and interviewed to work on jobs and complete project milestones. Thus, the activities within the entire project value chain are conducted digitally [14]. Some examples for major online labor markets are freelancer.com and upwork.com. A closely related concept is crowdsourcing, the "act of a company or institution taking a function once performed by employees and outsourcing it to an undefined (and generally large) network of people in the form of an open call" [17]. However, crowdsourcing emphasizes collaboration and problem-solving, often through "contests" [18] or "micro tasks" [19 - 20].

There has been a growing body of literature in the field of online labor markets. Studies in this field have focused on the differences regarding classical, "offline" labor markets, such as female hiring biases [21], country preferences [22], language, time-zone and cultural differences [23], and auction preferences, such as the influence of bid format sealed and closed bids - on buyer surplus [24]. There has been some literature on signaling in online labor markets, which we will review in the following chapters. We will organize the review by the type of signal - namely assessment and conventional signals - and review studies on both antecedents and outcomes of signals. 


\subsection{Signaling in online labor markets}

Recall that signaling is defined as a process in which "one party (termed the agent) credibly conveys some information about itself [through different signals] to another party (the principal)" [2]. Central to the concept of signaling is the cost associated with a signal. Spence [3] discussed an individual's education as a reliable signal because low performing individuals are not able to (successfully) obtain higher education and thus lack the ability to successfully send it. In other words, in the case of education, the costs associated with the signal outweigh the benefits for individuals that are not likely to succeed. The same is true for tests that can be taken on freelancing sites and are displayed publicly. Tests are a costly signal, because producing the signal without having the skills to take the test would not have benefits for the sender (a bad result is displayed on the page). We term these types of signals "assessment signals" - signals that are "reliable, because producing the signal requires possessing the indicated quality" [12]. The same is true for a freelancer's ratings and portfolio items. Showing portfolio items - samples of past projects would not be beneficial for the client if he or she has not been able to successfully perform his tasks in the past. If past projects did not end successfully or did not produce any outcome, showing portfolio items would not be beneficial or impossible. In general, portfolio items are directly verifiable as they are connected to a certain contract in the past. For an overview of assessment signals used in our study, see table 1 below.

Table 1. Assessment signals, definitions and examples from our dataset

\begin{tabular}{|c|c|c|}
\hline Signal & Definition & Example \\
\hline Tests & $\begin{array}{l}\text { The number of passed } \\
\text { knowledge tests as } \\
\text { displayed on each profile } \\
\text { site. }\end{array}$ & $\begin{array}{l}\text { Number of } \\
\text { passed tests for } \\
\text { different } \\
\text { Levels of PHP. }\end{array}$ \\
\hline $\begin{array}{l}\text { Portfolio } \\
\text { items }\end{array}$ & $\begin{array}{l}\text { Number of work } \\
\text { samples displayed on the } \\
\text { profile page. }\end{array}$ & $\begin{array}{l}\text { Links to } \\
\text { webpages, etc. }\end{array}$ \\
\hline Rating & $\begin{array}{l}\text { Average review score of } \\
\text { all projects completed, } \\
\text { range 1-5. }\end{array}$ & 4.85 Stars \\
\hline
\end{tabular}

In contrast to assessment signals, conventional signals do not require the sender to possess the quality signaled, rather, "the link between signal and quality is arbitrary, a matter of social convention" [12]. In other words, anyone could use e.g., his self- description to tell people about positive past events and his desirable qualities (self-promotion) or act like a favorable person by using flattery and being overly polite (ingratiation). Another conventional signal often used in OLM is the price of a product - only social mores or conventions prohibit freelancers to demand a higher price for their services. For an overview of the conventional signals used in our study, see table 2 .

Table 2. Conventional signals, definitions and examples from our dataset

\begin{tabular}{|c|c|c|}
\hline Signal & Definition & Example \\
\hline $\begin{array}{l}\text { Self- } \\
\text { Promotion }\end{array}$ & $\begin{array}{l}\text { Self-promotion } \\
\text { signals aim to show } \\
\text { that the subject/ } \\
\text { actor has desirable } \\
\text { qualities necessary } \\
\text { for the job through } \\
\text { anecdotes of past } \\
\text { events [25]. }\end{array}$ & $\begin{array}{l}\text { "In the past, I } \\
\text { have } \\
\text { successfully } \\
\text { finished many } \\
\text { projects based } \\
\text { on Pearl, Java } \\
\text { and PHP, e.g., } \\
\text { X, Y, Z." }\end{array}$ \\
\hline Ingratiation & $\begin{array}{l}\text { Ingratiation is a } \\
\text { signal intended to } \\
\text { evoke interpersonal } \\
\text { liking and } \\
\text { attraction between } \\
\text { the freelancer and } \\
\text { the client [26]. }\end{array}$ & $\begin{array}{l}\text { "I am always } \\
\text { available to } \\
\text { find ways we } \\
\text { can effectively } \\
\text { achieve your } \\
\text { desired goals." }\end{array}$ \\
\hline Price & $\begin{array}{l}\text { The average price } \\
\text { freelancers display } \\
\text { on their profile } \\
\text { page. }\end{array}$ & $65 \$ / \mathrm{hr}$ \\
\hline
\end{tabular}

\subsubsection{Assessment signals in OLM literature}

Recall that we have defined assessment signals as reliable, costly signals that can be directly validated by the receiver. We have pointed out earlier that we already observe a broad variety of literature on different types of assessment signals. Some studies have assessed the antecedents of assessment signals, such as skills [27], market threats and market concentration [28], contract type, motives [1] and various demographics [29 -30]. To date, research has not assessed the role of character traits regarding assessment signaling in online labor markets.

There are already some studies in extant literature that have applied signaling theory to explain online platform outcomes. Some of these studies have assessed the influence of assessment signals on performance outcomes such as consumers' willingness to transact [31] and perceptions of product quality [32]. An outcome studied widely in OLM literature are hiring decisions. Assessment 
signals addressed by this literature stream include the presence of an agency affiliation [33], the number of portfolio pieces [7], and the presence of a top rated status [8-9]. However, to our knowledge, there is no study assessing financial performance outcomes of signals in online labor markets.

\subsubsection{Conventional signals in OLM literature}

We have described earlier that conventional signals are not based on verifiable information and thus cannot be directly validated. These signals have been the subject of studies on impression management in an offline environment such as hiring, interviews and evaluations [34 - 37]. Research on antecedents of conventional signals in information science literature is scarce. However, a few articles indirectly referring to the use of conventional signals are concerned with outcome measures such as "envy" [38], "first impression bias" [39], "online isomorphism" [40] and "swift guanxi" - the creation of intimacy perceptions [41]. This stream does not differentiate between certain tactics and thus applies a unidimensional approach to conventional signaling. Research regarding the outcomes of conventional signals includes the effect of viewing social media profiles on subjective well-being and self-esteem [42 - 43] or evaluations of others [44 - 45]. In summary, it still remains unclear how conventional signaling in social media, particularly in online labor markets, is linked to individual work-related success measures.

\section{Hypotheses}

\subsection{Performance implications of signals}

According to signaling theory, information asymmetry between two parties can be reduced by sending costly market-related signals, which in turn, makes an existing contractual relationship more viable and helps to attract new customers [46-47]. Specifically, the freelancer needs to decide whether and how to provide relevant information toward a customer, who in turn interprets these signals [48].

Recall that assessment signals are difficult to be imitated by competitors and are only beneficial for the sender if he or she possesses the qualities to be signaled. Assessment signals require high costs and risks from the freelancer to transfer the signal in absence of authenticity [49]. Thus, these signals reduce information asymmetry through credible information such as portfolio items and tests and positively affect the freelancer - client relationship. Signals assessed within this category, are the increase of CEOs' ownership stakes to promote diversification strategies [50], the stack of a firm's board with prominent directors to signal legitimacy [51] and the establishment of heterogeneous boards to signal compliance with social values $[52,48]$.

In our case, the OLM provides some opportunities to engage in assessment signaling: References in the form of portfolio items, a quality rating provided by past customers and tests to showcase a freelancer's knowledge. In the light of signaling theory, all these signals should be costly and "hard to fake" and thus reliable indicators of true positive qualities. Thus, information asymmetry should be decreased which is beneficiary for sales and ultimately increases a freelancer's overall success measured by his earnings [14]. Thus, we hypothesize the following:

Hla: There is a positive association of the number of portfolio items with earnings.

H1b: There is a positive association of a freelancer's rating displayed on the page with earnings.

H1c: The number of tests displayed on the profile page is positively associated with a freelancer's earnings.

Unlike assessment signals, conventional signals are not directly linked to specific qualities, high costs and verifiable information. In contrast, only social conventions and mores (e.g., terms of conduct) may prevent the sender from providing exaggerated or false information. However, these "costs" are not high enough to guarantee honesty of the sender [12]. Consequently, research has assumed that these signals may be less reliable concerning the true qualities of the signaling-subject [49].

However, this rationale may not be universally true for all types of conventional signals. In contrast, consumer studies have shown that some conventional signals may increase short term sales performance. Advertising industry tries to convince potential customers by telling "success stories" including brand and store information [53]. Thus, we propose that some conventional signals might increase earnings if the customer associates them with beneficial facts about the freelancer. One such signal is a product's price, where a higher price incorporates notions of higher quality [53]. Likewise, selfpromotion - tactics that are used to create positive associations through anecdotes of past achievements - may also lead to a reduction of information asymmetry and increase credibility. We base this proposition on the fact that anecdotes of past achievements - especially in a freelancing 
environment that is mainly concerned with knowledge work - require at least some knowledge about the underlying techniques and thus incorporate reliable elements. In other words, freelancers with insufficient knowledge about the underlying techniques may not be able to form suitable anecdotes.

However, for freelancers engaging strongly in Ingratiation tactics - flattery behavior towards the customer - we do not expect a reduction in information asymmetry. In contrast, credibility is likely to decrease as a customer might get suspicious that the freelancer is trying to cover his negative qualities. This can be explained by attribution theory that deals with "how the social perceiver uses information to arrive at causal explanations for events" [54]. Attribution theory's discounting principle states that contractors in OLM are likely to accurately discount ingratiation for the presence of plausible ulterior motives in the situation (e.g., trying to sell services). This discounting for ulterior motives ultimately results in lower perceptions of the trustworthiness of the freelancer [55]. Thus, we hypothesize the following:

H2a: The amount of ingratiation tactics use is negatively associated with a freelancer's earnings.

$H 2 b$ : There is a positive association of the amount of self-promotion tactics with earnings.

H2c: The price is positively associated with a freelancer's earnings.

\subsection{Other factors affecting earnings}

Besides the signals described before, other factors are likely to affect earnings in OLM. One such factor are specific character traits that are correlated with entrepreneurial behavior and innovativeness. These traits have been shown to affect peoples' behavior [56]. Five "cardinal traits" - also called the "Big Five" - have been defined in extant literature: extraversion, agreeableness, neuroticism, conscientiousness and openness to experience [56]. Among these five traits, two have been shown to be good proxies for entrepreneurial behavior and innovativeness - extraversion and openness [57]. Moreover, the configuration of these traits might also affect how conventional signals are sent, e.g. research on social networks has shown that extroverted people tend to transfer their behavior from real to virtual life by providing information on profile pages differently and more extensive [42 - 45]. Thus, we will assess these traits as a moderator of the conventional signal
- earnings relationship. Besides the influence of traits, the individual skill and experience set of the freelancer such as the level of verbal proficiency in english, the educational level, level of availability on the platform and past project experience - the number of past projects - might be an important determinant of earnings and are included as control measures.

\section{Method}

To assess the proposed relationships, we gather three types of data - survey data of traits, objective data of earnings, assessment signals and the price gained directly from a freelancing platform and independent codings of self-promotion and ingratiation.

As a first step, we used web crawling technology to generate a list of 56.000 freelancers from a major freelancing platform. To ensure random sampling, the crawler used each of more than 3,000 fine grained skill-tags gathered from the platform to search for candidates and saved each freelancers' publicly accessible information in an SQL database. To ensure that no duplicates are saved, respective code was added to the crawler. As a result, we were able to obtain a random database of over 56.000 unique freelancer profiles.

In a second step, we drew a random sub-sample from the original list to generate candidates that received an invitation to take part in the survey. An incentive of $\$ 5$ was given to reduce non-response bias. This procedure resulted in 1174 completed questionnaires. We repeated the crawling process for the earnings measure after one year and were able to gain earnings data from all past projects a freelancer engaged in for the period of one year after the first measurement. This procedure enabled us to spot inactive users or fake profiles.

After merging survey and objective data, we obtained independent codings from three judges that rated each freelancer's signaling behavior based on their self-descriptions posted on the profile page. Our obtained dataset was reduced as we excluded (a) inactive users (b) suspended / deleted users (c) users lacking a rating (d) users with incomplete information. The final dataset included 1065 users.

\subsection{Sample}

Our final sample of 1,065 freelancers contains $29 \%$ females and $71 \%$ males. The major proportion $-39 \%$ - of freelancers contained in the sample were located in the indian subcontinent (India, Pakistan, Bangladesh etc.), the second largest proportion was Asia (22\%) while 16\% accounted for developed 
countries (Western Europe, Australia, USA) and 15\% for Eastern Europe (Russia, Ukraine, Poland, Baltic States etc.), 9\% were freelancers from other regions. Regarding the educational level, 52\% of the freelancers had an undergraduate degree, $32 \%$ hold a graduate degree with $1.4 \%$ holding a postgraduate and $7.9 \%$ holding high school or lower degree, $6.5 \%$ had another type of degree. Descriptive statistics of other variables included in our model are depicted in table 3.

Table 3: Descriptive Statistics

\begin{tabular}{llll}
\hline & Mean & SD & N \\
\hline Earnings & 2383.66 & 4930.35 & 1065 \\
Tests & 3.04 & 4.74 & 1065 \\
Rating & 4.84 & .32 & 1065 \\
Price & 14.42 & 11.96 & 1065 \\
Availability & 4.51 & .75 & 1065 \\
Ingratiation & 2.04 & 1.02 & 1065 \\
Self-promotion & 3.08 & .92 & 1065 \\
Portfolio items & 7.39 & 13.64 & 1065 \\
Project & & & \\
Experience & 22.84 & 29.15 & 1065 \\
\hline
\end{tabular}

\subsection{Measures}

To assess earnings, we collected the job history of each freelancer in our final sample containing jobs started from January 2015 - January 2016. In a second step we aggregated the earnings over each freelancer, thus transforming wide project level to individual level data. Accordingly, we were able to collect earnings information for each freelancer for the year after the signaling information and all other measures were collected.

Moreover, we collected the project experience in terms of the number of projects completed on the platform for each freelancer and the self-rated availability of the freelancer on the platform (likert scale ranging from 1-5 with 5 referring to the highest measure of availability on the site).

The trait measures reflect existing scales developed in prior research and were assessed on the basis of the big five personality traits-openness to experience and extraversion. For this purpose, we used the non-reverse coded items of the standard IPIP scale for extraversion (5 items) and openness (7 items) [56]. Sample items include "I am the life of the party." (extraversion) and "I have a vivid imagination." (openness). Subjects were asked how well these items described them on a 7 point likert scale ranging from "(1) strongly disagree" to “(7) strongly agree”. Cronbach's alpha was above .7 for all items.

Self-promotion and Ingratiation signals were measured through independent coding of the selfdescriptions present on each freelancer's profile page. The coding is conducted by three independent coders applying the consensual assessment technique described by Amabile [58]. Building on the respective definitions (see Table 2), coders were trained to rate each self-description regarding the intensity of the form of signaling behavior from (1) not at all to (7) very intense. Thus, we gained each coder's scores for each freelancer. We calculated the respective average ICC measure. All ICC values were above the value of .6 suggesting good overall consistency of the codings allowing us to average them to a single measure. The number of tests, the rating, the number of portfolio items and the price are obtained directly from the profile pages as objective measures.

\subsection{Analysis}

As we had to deal with a count outcome variable, parametric tests, such as linear regression are not sufficient. In contrast, poisson regression models and negative binomial models better approximate a right skewed distribution as present in count outcomes. As the dispersion parameter exceeded the value of 0 in all our models and deviance exceeded critical cut off levels, we concluded that negative binomial regression is more sufficient to test our hypotheses than poisson regression. To better interpret our findings we calculated the $\operatorname{Exp}(b)$ coefficients. The latter represent odds-ratios that can be interpreted by multiplying them with the DV to approximate the effect of a one-unit IV increase. Thus, any value $>1.00$ represents a positive impact and every value $<1.00$ indicates a negative impact on the outcome variable.

\section{Results}

The results of our regression model can be found in Table 4. As expected, we can observe significant positive effects of individual differences such as english verbal proficiency (english level) and number of completed projects. The degree of availability of the freelancer on the site was also significantly related to higher earnings. Moreover, we observed significant country differences for freelancers from Asia $(\operatorname{Exp}(b)=2.739, p=.000)$ and $\operatorname{India}(\operatorname{Exp}(b)=$ 
1.675, $\mathrm{p}=.029)$. However, we observed no direct effect of traits and no moderating effects leading us to discard the moderation model.

Table 4: Effect of skills, traits and signals on freelancers' 1-year earnings in USD - negative binomial regression. ${ }^{1}$

\begin{tabular}{|c|c|c|c|}
\hline & Model 1 & Model 2 & Model 3 \\
\hline \multicolumn{4}{|l|}{ Controls } \\
\hline Availability & $1.356 * * *$ & $1.375 * * *$ & $1.545^{* * * *}$ \\
\hline Experience & $1.020 * * *$ & $1.020 * *$ & $1.020 * * *$ \\
\hline \multicolumn{4}{|l|}{ Education } \\
\hline [No Degree] & .134 & .119 & .190 \\
\hline [High School] & 1.080 & 1.004 & 1.143 \\
\hline [Bachelor] & .845 & .822 & .778 \\
\hline [Master] & 1.094 & 1.095 & .889 \\
\hline [Doctorate] & .692 & .576 & .485 \\
\hline \multicolumn{4}{|l|}{ Country } \\
\hline [India] & 1.315 & 1.272 & $1.675^{*}$ \\
\hline [Asia] & $1.992 * *$ & $1.949 * *$ & $2.739 * * *$ \\
\hline [Developed] & 1.637 & 1.621 & 1.220 \\
\hline [East Europe] & $1.862 *$ & $1.748 *$ & 1.590 \\
\hline Gender & .806 & .809 & 1.021 \\
\hline English Level & $1.575^{* *}$ & $1.582 * *$ & $1.557 * *$ \\
\hline \multicolumn{4}{|l|}{ Traits } \\
\hline Extraversion & & .933 & .921 \\
\hline Openness & & .921 & 1.009 \\
\hline \multicolumn{4}{|l|}{ Signals } \\
\hline Portfolio & & & $.991 *$ \\
\hline Rating & & & .978 \\
\hline Tests & & & $1.041 * *$ \\
\hline Ingratiation & & & $.873 *$ \\
\hline Self-Promotion & & & $1.277 * * *$ \\
\hline Price & & & $1.047 * * *$ \\
\hline $\mathrm{N}$ & 1,065 & 1,065 & 1,065 \\
\hline Dispersion P.. & 3.591 & 3.580 & 3.412 \\
\hline df & 13 & 2 & 6 \\
\hline delta -2LL & $120.76 * * *$ & 4.68 (n.s) & $74.14 * * *$ \\
\hline
\end{tabular}

Significance levels: $* * * \mathrm{p}<.001 * * \mathrm{p}<.01 * \mathrm{p}<.05$

${ }^{1} \operatorname{Exp}(\mathrm{B})$ values are displayed. Education, Country and Gender are dummy coded, baseline groups: Other education, other country and male.

Inspection of the $-2 \mathrm{LL}$ ratio deltas reveals that signals add explanative value compared to Model 1 .
However, H1a and H1b could not be confirmed in our analysis. Besides an initially (weak) positive correlation $(\mathrm{r}=.061, \mathrm{p}=.04)$, portfolio items had a slightly negative significant impact on earnings. At the same time the variable was correlated with past experience $(\mathrm{r}=.354, \mathrm{p}<.01)$. Thus, we assume a suppression effect of past experience. Moreover, we find no significant influence of the rating on a freelancer's earnings. However, as seen in table 3 (mean rating $=4.84$ ), a possible explanation of this non-finding could be upward biases present in OLM - we will elaborate further on that in the discussion section.

H1c was confirmed showing a significant positive effect of adding tests on earnings. Accordingly - as shown by the odds ratio in Table 4 , adding one test to the profile increases earnings by $4.1 \%$.

For $\mathrm{H} 2 \mathrm{a}$ - the negative influence of ingratiation we can observe a significant negative effect, leading us to accept the hypothesis. $\mathrm{H} 2 \mathrm{~b}$ and $\mathrm{H} 2 \mathrm{c}$ were confirmed: Self-promotion tactics and increased price showed a significant positive association with earnings.

\section{Discussion}

Our analysis shows that self-promotion, price and the number of tests taken by a freelancer are valid predictors of a freelancer's performance in terms of 1 -year earnings in OLM. For ingratiation tactics flattery behavior towards the customer - we see a negative effect on earnings. We find no significant earnings impact of the freelancers' rating. Prior research on hiring decisions has pointed to a potential upward bias in ratings reducing their effect on information asymmetry and ultimately their predictive validity in terms of performance. We can particularly confirm this finding through our analysis. Before risking a bad rating and potential reputation flaws, freelancers may offer their clients to reduce the charge in exchange for a good rating. Thus, its ability to reduce information asymmetry decreases. However, we find other signals to be positively associated with earnings.

First, we propose that customers should more carefully look at less structured signals that freelancers send via their profile pages, especially in self-descriptions. In fact, the use of self-promotion tactics - a conventional signal - shows a significant positive impact on performance in terms of 1-year earnings. With every unit increase of self-promotion, the odds-ratio suggests earnings to rise by $27 \%$.

However, if conventional signaling is based on ingratiation tactics, such as flattery, we find a negative association with earnings - a unit increase in 
ingratiation lowers the earnings by $13 \%$. In a supplementary analysis, we let three independent coders judge each freelancer according to their overall impression of credibility on a 7-point scale using consensual assessment as described in the method section ("According to your impression, how credible do you think this freelancer is?", ICC > .6). We found that credibility showed a significant positive correlation with self-promotion $(\mathrm{r}=.38, \mathrm{p}=$ .000). These findings support our argument that the way people describe themselves seems to matter in OLM, particularly for the successful formation of contracts and freelancing success - even if these descriptions are not directly verifiable. Thus, in search for suitable freelancers, customers should pay attention to self-descriptions and the conventional signaling tactics employed.

Second, the suppression effect of experience on portfolio items shows that the project experience on the platform is a driver of earnings rather than references shown on the profile page.

Third, we find that the number of tests taken by a freelancer is significantly associated with higher earnings - adding a test score to the profile is associated with a $4.1 \%$ increase in earnings. This finding points to the number of knowledge tests performed by a freelancer as a viable measure for assessment.

The finding that a higher price is associated with higher earnings could be interpreted twofold: On the one hand, price is a natural driver of higher earnings. On the other hand, in our dataset, price was explicitly measured as a signal (the price displayed on top of the page). This price is not identical to the average price of past projects. This opens up avenues for further research on the role of price as a signal in OLM.

Moreover, future studies could include the assessment of long term financial data through methods such as time series and add dyadic performance evaluations of customers to capture a broader variety of performance measures. It was not the focus of the current study to assess the influence of character traits on the choice of signals. However, it might be promising for future research to extend the set of character trait and skill variables that might affect how freelancers send signals in OLM. Regarding the role of character traits, we propose that future research might apply different assessment techniques apart from self-rated measures. Though we used a major freelancing platform with a high market share, we were restricted to a single platform to assess our model. Future research could extend the model to other platforms or combine multiple platforms. Last but not least, the assessment of self- descriptions did not allow us to assess defensive or reactive signals, such as disclaimers. Thus, future research could extend the range of conventional signals and assessment signals to include defensive signaling tactics.

Our research leads to different implications: We enable freelancers to better market their services by showing the potential and bandwidth of various types of signals - especially conventional signals. At the same time, clients may infer crucial job-related factors from signaling activities to improve their hiring decisions. Last but not least, our research has implications for the design of OLM platforms in terms of optimizing the positioning of signaling opportunities on the site according to their relevance.

\section{Conclusion}

In this study, we assessed alternative predictors of performance in OLM. In summary, we show, that both forms of signals - assessment as well as conventional signals - show the potential to reduce information asymmetry in OLM. Among others, the number of knowledge tests passed by the freelancer and the amount of self-promotion seem to predict performance in terms of increased 1-year earnings and may guide customers' decisions for hiring freelancers in online labor markets. In contrast, we find initial evidence that ingratiation tactics, such as flattery towards the customer, are negatively associated with earnings.

\section{References}

[1] Farrell, A. M., J. H. Grenier and J. Leiby, „Scoundrels or stars? Theory and evidence on the quality of workers in online labor markets", The Accounting Review (92:1), 2016, pp. 93-114.

[2] Matsubara, S., and R. Kagifuku, "Reducing congestions in decentralized matching by using preference signaling", Proceedings of the 18th Annual International Conference on Electronic Commerce: e-Commerce in Smart connected World (2016:1), 2016, pp. 38-38.

[3] Spence, M., “Job market signaling”, Quarterly Journal of Economics (87:3), 1973, pp. 355-374.

[4] Glazer, A., and K. A. Konrad, "A signaling explanation for charity", The American Economic Review, (86:4), 1996, pp. 1019-1028.

[5] Leland, H.E., and D. H Pyle, "Informational asymmetries, financial structure, and financial intermediation", The journal of Finance (32:2), 1977, pp. 371-387. 
[6] Waldfogel, J., and L. Chen, "Does Information Undermine Brand? Information Intermediary Use and Preference for Branded Web Retailers", Journal of Industrial Economics (54:4), 2006, pp. 425-449.

[7] Lin, M., Y. Liu, and S. Viswanathan, "Effectiveness of reputation in contracting for customized production: Evidence from online labor markets", Management Science, Published online in articles in advance 16 Dec 2016.

[8] Assemi, B., and D. Schlagwein, "Provider feedback information and customer choice decisions on crowdsourcing marketplaces: Evidence from two discrete choice experiments", Decision Support Systems (82:1), 2015, pp. 1-11.

[9] Banker, R. D., and I. Hwang, "Importance of Measures of Past Performance: Empirical Evidence on Quality of e-Service Providers", Contemporary Accounting Research (25:2), 2008, pp. 307-337.

[10] Moreno, A., and C. Terwiesch, "Doing business with strangers: Reputation in online service marketplaces", Information Systems Research (25:4), 2014, pp. 865-886.

[11] Snir, E. M., and L.M. Hitt, "Costly bidding in online markets for IT services", Management Science, (49:11), 2003, pp. 1504-1520.

[12] Donath, J., "Signals in social supernets", Journal of Computer-Mediated Communication (13:1), 2007, pp. 231251.

[13] O'Toole, T., and B. Donaldson, "Relationship performance dimensions of buyer-supplier exchanges", European Journal of Purchasing and Supply Management (8:4), 2002, pp. 197-207.

[14] Holthaus, C. and R. M. Stock, "Performance and Trait Implications of Signaling in Online Labor Markets" Research in Progress Report, unpublished, 2017.

[15] Healy, P. M., K.G. Palepu, and R.S. Ruback, "Does corporate performance improve after mergers?", Journal of Financial Economics (31:2), 1992, pp. 135-175.

[16] Bölte, S., E. Westerwald, M. Holtmann, C. Freitag, and F. Poustka, ,Autistic traits and autism spectrum disorders: The clinical validity of two measures presuming a continuum of social communication skills", Journal of Autism and Developmental Disorders (41:1), 2011, pp. 6672.

[17] Schenk, E., and C. Guittard, "Towards a characterization of crowdsourcing practices", Journal of Innovation Economics and Management (1:1), 2011, pp. 93-107.

[18] Brabham, D. C., "Moving the crowd at iStockphoto: The composition of the crowd and motivations for participation in a crowdsourcing application", First Monday (13:6), 2008, pp. 1-1.

[19] Heer J., and M. Bostok, "Crowdsourcing graphical perception: using mechanical turk to assess visualization design", Proceedings of the 28th International Conference on Human Factors in Computingsystems (2010:1), 2010, pp. 203-212.
[20] Heymann, P., and H. Garcia-Molina, "Turkalytics: analytics for human computation", Proceedings of the 20th International Conference on World Wide Web (2011:1), 2011, pp. 477-486.

[21] Chan, J., and J. Wang, "Hiring preferences in online labor markets: Evidence of a female hiring bias", Management Science, 2017, Forthcoming.

[22] Gefen, D., and E. Carmel, "Is the world really flat? A look at offshoring at an online programming marketplace", MIS Quarterly (32:2), 2008, pp. 367-384.

[23] Hong, Y., and P. A. Pavlou, "On Buyer Selection of Service Providers in Online Outsourcing Platforms for IT Services", Information Systems Research, 2017, Forthcoming.

[24] Hong, Y., C. Wang, and P. A. Pavlou, "Comparing open and sealed bid auctions: Evidence from online labor markets", Information Systems Research (27:1), 2015, pp. 49-69.

[25] Lee, S. J., B.M. Quigley, M.S. Nesler, A.B. Corbett, and J. T. Tedeschi, "Development of a self-presentation tactics scale", Personality and Individual Differences (26:4), 1999, pp. 701-722.

[26] Ellis, A. P., B. J. West, A.M. Ryan, and R. P. DeShon, "The use of impression management tactics in structured interviews: a function of question type?", Journal of Applied Psychology (87:6), 2002, pp. 1200-1208.

[27] Protsch, P., and H. Solga, "How Employers Use Signals of Cognitive and Noncognitive Skills at Labour Market Entry: Insights from Field Experiments", European Sociological Review (31:5), 2015, pp. 521-532.

[28] Guo, W., T. Yu, and J. Gimeno, "Language and Competition: Exploring the Antecedents and Consequences of Firm Verbal Signals", Academy of Management Proceedings (2014: 1), 2014, pp. 17326.

[29] Mill, R., "Hiring and Learning in Online Global Labor Markets", NET Institute Working Papers (11:17), 2011, pp. 1-34.

[30] Paolacci, G., J. Chandler, and P. G. Ipeirotis, "Running experiments on Amazon Mechanical Turk", Judgment and Decision Making (5:5), 2010, pp. 411-419.

[31] Gregg, D. G., and S. Walczak, "Dressing your online auction business for success: An experiment comparing two eBay businesses", MIS Quarterly (32:3), 2008, pp. 653-670.

[32] Wells, J. D., J. S. Valacich, and T. J. Hess, "What signal are you sending? How website quality influences perceptions of product quality and purchase intentions", MIS Quarterly (35:2), 2011, pp. 373-396.

[33] Stanton, C. T., and C. Thomas, "Landing the first job: The value of intermediaries in online hiring", Review of Economic Studies (83:2), 2015, pp. 810-854.

[34] Tedeschi, J. T., and V. Melburg, "Impression management and influence in the organization", in Research in the sociology of organizations, Bachrach S.D., and Lawler, E.J. (eds.), 1984, pp. 31-58. 
[35] Tedeschi, J. T., and N. Norman, "Social power, selfpresentation, and the self", in The Self and Social Life, Schlenker, B.R. (Ed.), 1985, pp. 293-322.

[36] Wayne, S. J., and R. C. Liden, "Effects of impression management on performance ratings: A longitudinal study", Academy of Management Journal (38:1), 1995, pp. 232-260.

[37] Kacmar, K.M., and D.S. Carlson, "Effectiveness of Impression Management Tactics across Human Resource Situations", Journal of Applied Social Psychology (29:6), 1999, pp. 1293-1311.

[38] Krasnova, H., T. Widjaja, P. Buxmann, H. Wenninger, and I. Benbasat, "Research note-why following friends can hurt you: an exploratory investigation of the effects of envy on social networking sites among college-age users", Information Systems Research (26:3), 2015 , pp. 585-605.

[39] Lim, K. H., I. Benbasat, and L.M. Ward, "The role of multimedia in changing first impression bias", Information Systems Research (11:2), 2000, pp. 115-136.

[40] Pant, G., and O.R. Sheng, "Web footprints of firms: Using online isomorphism for competitor identification", Information Systems Research (26:1), 2015, pp. 188-209.

[41] Xiaojuan Ou, C., P. A. Pavlou, and R. Davison, "Swift guanxi in online marketplaces: The role of computermediated communication technologies", MIS Quarterly (38:1), 2014, pp. 209-230.

[42] Gonzales, A. L., and J. T. Hancock, "Mirror, mirror on my Facebook wall: Effects of exposure to Facebook on self-esteem", Cyberpsychology, Behavior, and Social Networking (14:1-2), 2011, pp. 79-83.

[43] Kim, J., and J. Lee, "The Facebook paths to happiness: Effects of the number of Facebook friends and selfpresentation on subjective well-being", Cyberpsychology, Behavior, and Social Networking (14:6), 2011, pp. 359364.

[44] Tong, S. T., B. Van der Heide, L. Langwell, and J. B. Walther, "Too much of a good thing? The relationship between number of friends and interpersonal impressions on Facebook", Journal of Computer-Mediated Communication (13:3), 2008, pp. 531-549.

[45] Walther, J. B., B. Van der Heide, S. Y. Kim, D. Westerman, and S. T. Tong, "The role of friends' appearance and behavior on evaluations of individuals on Facebook: Are we known by the company we keep?", Human Communication Research (34:1), 2008, pp. 28-49.

[46] Mavlanova, T., R. Benbunan-Fich, and M. Koufaris, "Signaling theory and information asymmetry in online commerce", Information and Management (49:5), 2012, pp. 240-247.

[47] Myers, S. C., and N. S. Majluf, "Corporate financing and investment decisions when firms have information that investors do not have", Journal of Financial Economics (13:2), 1984, pp. 187-221.

[48] Connelly, B. L., S. T. Certo, R. D. Ireland, and C. R. Reutzel, "Signaling theory: A review and assessment", Journal of Management (37:1), 2011, pp. 39-67.
[49] Shami, N. S., K. Ehrlich, G. Gay, and J. T. Hancock, "Making sense of strangers' expertise from signals in digital artifacts", Proceedings of the SIGCHI Conference on Human Factors in Computing Systems (2009:1), 2009, pp. 69-78.

[50] Goranova, M., T. M. Alessandri, P. Brandes, and R. Dharwadkar, "Managerial ownership and corporate diversification: A longitudinal view", Strategic Management Journal (28:3), 2007, pp. 211-225.

[51] Certo, S. T., "Influencing initial public offering investors with prestige: Signaling with board structures", Academy of Management Review (28:1), 2003, pp. 432446.

[52] Miller, T., and M. D. Triana, "Demographic diversity in the boardroom: Mediators of the board diversity - firm performance relationship", Journal of Management Studies (46:5), 2009, pp. 755-786.

[53] Dodds, W. B., K. B. Monroe, and D. Grewal, "Effects of price, brand, and store information on buyers' product evaluations", Journal of Marketing Research (28:3), 1991, 307-319.

[54] Fiske, S. T., and S. E. Taylor, "McGraw-Hill series in social psychology. Social cognition", New York: McGrawHill Book Company, 1991.

[55] Main, K. J., "Consumer responses to flattery during sales transactions: Empirical evidence of the sinister attribution error", Doctoral dissertation, University of British Columbia, 2004.

[56] Costa, P. T., and R. R. McCrae, "Four ways five factors are basic", Personality and Individual Differences, (13:6), 1992, pp. 653-665.

[57] Yesil, S., and F. Sozbilir, "An empirical investigation into the impact of personality on individual innovation behaviour in the workplace", Procedia - Social and Behavioral Sciences (81:1), 2013, pp. 540-551.

[58] Amabile, T. M., "A consensual assessment technique", Journal of Personality and Social Psychology (43:1), 1982, pp. 997-1013. 